\title{
Novel Hybrid SETMOS Logic for Ultra-low-power Applications
}

Raj Sanjivkumar Shah ( $\nabla$ d16ec005@eced.svnit.ac.in )

Sardar Vallabhbhai National Institute of Technology https://orcid.org/0000-0001-9557-6173

\section{Rutu Parekh}

DAIICT: Dhirubhai Ambani Institute of Information and Communication Technology

\section{Rasika Dhavse}

Sardar Vallabhbhai National Institute of Technology

\section{Research Article}

Keywords: Coulomb-Blockade, MIB-Model, Quantum- Mechanical-Tunneling, SETMOS-Hybridization, Silicon-Single-Electron-Transistor, Ultra-Low-Power-Circuits

Posted Date: November 8th, 2021

DOI: https://doi.org/10.21203/rs.3.rs-1002126/v1

License: (c) (i) This work is licensed under a Creative Commons Attribution 4.0 International License. Read Full License 


\title{
Novel Hybrid SETMOS Logic for Ultra-low-power Applications
}

\author{
Raj Shah · Rutu Parekh · Rasika Dhavse
}

Received: date / Accepted: date

\begin{abstract}
This paper investigates the Single-Gate Single Electron Transistors (SG-SETs) based hybrid SETMOS logic circuits for ultra-low-power applications at room temperature. The methodological design of the proposed hybrid SETMOS logic circuits is compatible with 22- nm CMOS bias and process. The widely acclaimed Mahapatra-IonescuBannerjee (MIB) model is modified to implement the proposed SG-SET and hybrid SETMOS logic circuits using Verilog-A. Logic inverter, two-input NAND, NOR, AND, OR, EX-OR, and EX-NOR logic gates are simulated at room temperature using novel SETMOS hybridization. The proposed work is compared with the 22-nm CMOS counterpart (simulated with the same setup). We found that the reduction in total power dissipation by $98.04 \%, 96.45 \%, 94.65 \%$, 93.7\%, 92.63\%, 93.52\%, 95.57\% using hybrid SETMOS NAND, NOR, AND, EX-OR and EXOR gates than $22 \mathrm{~nm}$ CMOS logic gates. The proposed work is compared with other works of literature. We also examined the robustness of the proposed logic circuits against temperature variations from $77 \mathrm{~K}$ to $500 \mathrm{~K}$.
\end{abstract}

Keywords Coulomb-Blockade · MIB-Model · QuantumMechanical-Tunneling $\cdot$ SETMOS-Hybridization $\cdot$ SiliconSingle-Electron-Transistor · Ultra-Low-Power-Circuits

\section{Raj Shah}

Electronics Engineering Department, Sardar Vallabhbhai National Institute of Technology, Surat, Gujarat, India.

Tel.: +91-9712254402

E-mail: d16ec005@eced.svnit.ac.in

Rutu Parekh

Dhirubhai Ambani Institute of Information and Communication Technology, Gandhinagar, Gujarat, India.

E-mail: rutu_parekh@daiict.ac.in

Rasika Dhavse

Electronics Engineering Department, Sardar Vallabhbhai National Institute of Technology, Surat, Gujarat, India.

E-mail: rsk@eced.svnit.ac.in

\section{Introduction}

Beyond-Complementary Metal Oxide Semiconductor (CMOS) nanodevices have been investigated remarkably for ultralow-power applications for many years, essentially for CMOS extension and replacement. The degradation in the CMOS performance begins by virtue of technology scaling. The requirement of ultra-low-power dissipation in applications is of the utmost demand. This process eventually opens the door for novel nanodevices to succeed CMOS or hybridize with existing technology. In the era of nanoelectronics, Single Electron Transistors (SETs) can be the most promising nanodevice for logic as well as memory applications $[1,2]$. SET is working on quantum physics principles: Coulomb Blockade (CB) and Quantum Mechanical Tunneling (QMT) $[3,4]$. The low current drive, low supply voltage, small critical dimensions due to aF range total capacitance, and room temperature operations were the issues for CMOS compatibility [5-8]. However, the past two decades witnessed significant research work to attain and overcome many of these issues [8-18]. Research to exhibit room temperature behavior analogous to a conventional MOSFET and its demonstration for application in logic and memory circuits is still in infancy. The proper design methodology from device-level engineering to circuit design is a need. The advantage of silicon processing further enhancing the SET to hybridize with existing CMOS for ultra-low-power dissipation without losing the functionality $[9,11,19,20]$.

In our previous work, we have explored many hybridization techniques, and we ascertained that the Single Gate SET (SG-SET) as pull-down network and P-type MOS (PMOS) as pull-up network technique shows the best result in terms of ultra-low-power consumption and higher speed than contemporary techniques [20]. The CMOS compatibility and silicon processes are also advantages [20]. This hybridization method gives ultra-low-power consumptions than CMOS 
and lesser propagation delay than other SETMOS hybridization techniques [20, 21]. Also, using this kind of hybridization, co-tunneling can be avoided compared to SET-only based circuits [6]. Our earlier work also comprises the device planning and optimization of SG-SET using TCAD simulation, observing $\mathrm{CB}$ and QMT at room temperature, and mathematical modeling to express the drain current using Gibbs free energy[21, 22]. The tunnel resistance, $\mathrm{R}_{T}$ is also extracted as $20 \mathrm{M} \Omega$. This high range of $\mathrm{R}_{T}\left(>h / e^{2}\right)$ also ensures localization of electrons [6]. Hence, there are no assumptions made for any parameters in the proposed design. Experimental results imply that stray charges have less influence on silicon single-electron devices due to the charge screening effect compared to metal single-electron devices [23].

In this work, the logic circuits using the proposed technique are investigated for their applicability in ultra-low power applications. The novel hybrid SETMOS logic is implemented in Cadence Virtuoso using modified MIB of SG-SET and $22 \mathrm{~nm}$ PMOS predictive technology model (PTM) model $[24,25]$. The logic inverter and two input NAND, NOR, AND, EX-OR, EX-NOR gates are simulated at room temperature. Similarly, the 22-nm CMOS logic gates are simulated using the same simulation set-up to compare the total power consumption. The hybrid logic circuits are also compared with other works of literature, and then the thermal analysis is done for $77 \mathrm{~K}, 150 \mathrm{~K}, 300 \mathrm{~K}$, and $500 \mathrm{~K}$ temperatures.

\section{Simulation Methodology}

Fig.1a shows the SG-SET structure with its critical dimensions simulated in TCAD [21]. The tunnel barrier optimization and island engineering techniques have been carried out to obtain the best dimensions and materials for tunnel junctions and island of SG-SET [19, 21, 26]. The roomtemperature output characteristic is plotted and then calibrated with fabricated devices, as shown in Fig.1b. The CB of $\pm 0.8 \mathrm{~V}$ is observed from the characteristics. Also, the calibration shows good compatibility with fabricated devices as $\mathrm{CB}$ voltage and the range of drain current is similar. Fig. $2 \mathrm{a}$ shows the symbol and RC model of SG-SET. The SG-SET parameters are evaluated based on the criteria of room temperature operation, and CMOS bias compatibility [21]. The gate capacitance calculated from CMOS bias $\left(\mathrm{e} / 2 \mathrm{~V}_{D D}\right)$ is $0.1 \mathrm{aF}$. The tunnel junction capacitance is calculated from the parallel plate model as $0.0468 \mathrm{aF}$ [21] from TCAD simulations. This gives total capacitance $\left(\mathrm{C}_{\Sigma}=\mathrm{C}_{G}+2 \mathrm{C}_{J}\right)$ of 0.193 $\mathrm{aF}$ [21]. This also manifests the electrostatic energy $\left(\mathrm{E}_{C}=\right.$ $\left.\mathrm{e}^{2} / \mathrm{C}_{\Sigma}\right)[5,10,18-20,26,27]$ nearly 32 times higher than room temperature energy. The electrostatic energy $\left(\mathrm{E}_{C}\right)$ of SET should be 30-40 times higher than thermal energy for logic and 10-20 times higher for memory application to avoid

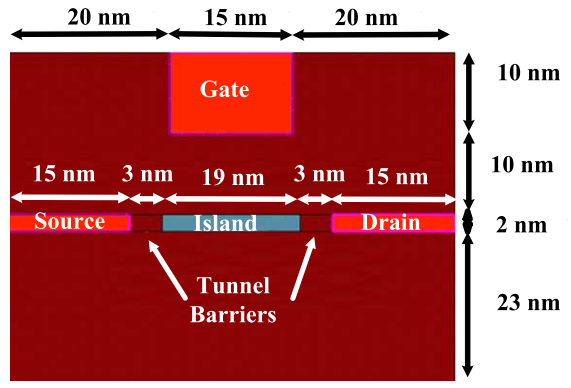

(a)

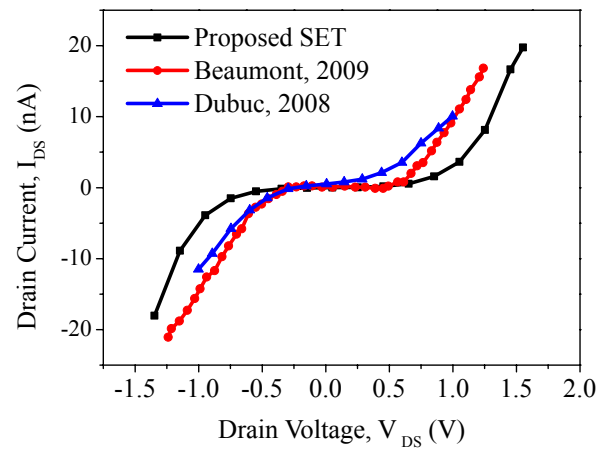

(b)

Fig. 1: SG-SET (a) structure and its critical dimensions [21] (b) Output characteristics at room temperature and calibration with fabricated SETs

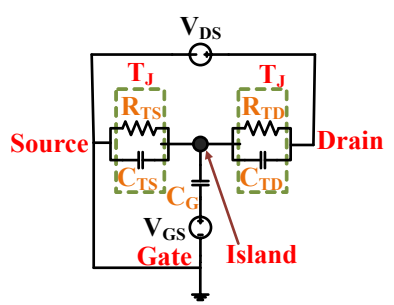

(a)

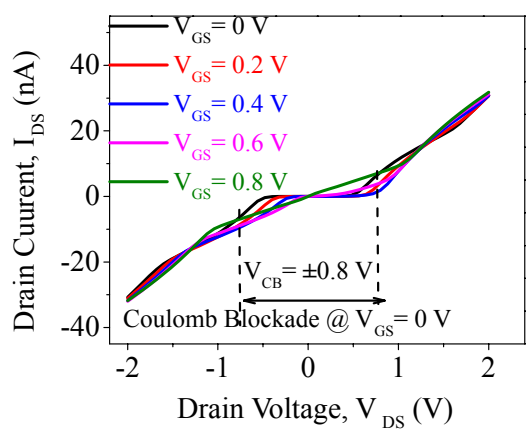

(b)

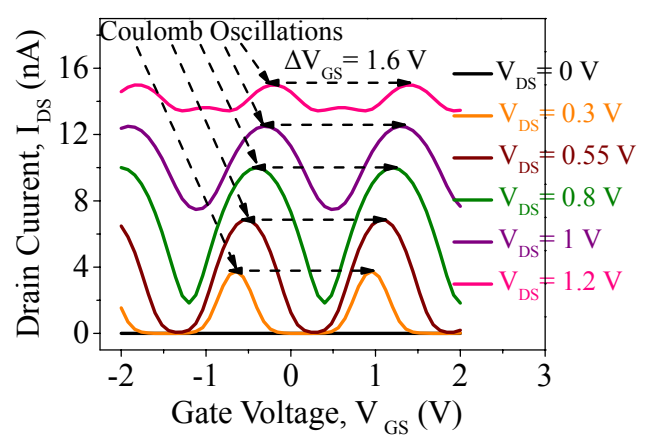

(c)

Fig. 2: SG-SET (a) RC model (b) output characteristics and (c) transfer characteristics ; at room temperature 
thermal conduction [10, 20, 27]. The Mahapatra-IonescueBannerjee (MIB) model [10], which is widely adopted for SET, is modified for SG-SET. The Verilog-A interface is used to implement SG-SET in Cadence Virtuoso for simulation. The modified MIB model is used to validate the TCAD results and gives accurate extraction of the tunnel resistance (20 $\mathrm{M} \Omega$ ) [21]. Fig.2b and Fig.2c show the output and transfer characteristics plotted at room temperature. The output characteristics clearly observed the CB for $\pm 0.8 \mathrm{~V}$ for zero gate voltage and then QMT overhauls CB [21]. The Coulomb oscillations analyzed in the transfer characteristics which is the signature property of the device. The gap of oscillation is $1.6 \mathrm{~V}$ which gives the gate capacitance of $0.1 \mathrm{aF}$; similar to estimated theoretically [21].

\subsection{Simulation Method of Novel Hybrid SETMOS}

Fig.3a shows the hybrid SETMOS logic inverter. For the logic inverter, the load capacitance is $30 \mathrm{aF}$ calculated by summing intrinsic and extrinsic capacitances [21, 28]. Fig.3b shows the transient analysis simulated with a $100 \mathrm{MHz}$ clock signal that verified the functionality of the inverter. The extracted total power dissipation is $3.11 \mathrm{nW}$. Fig. $3 \mathrm{c}$ shows the

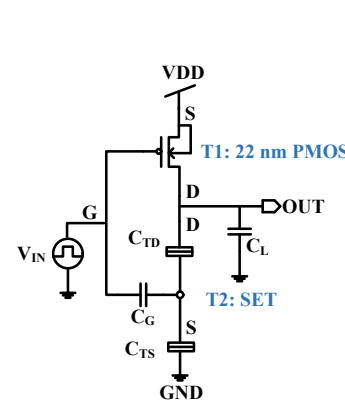

(a)

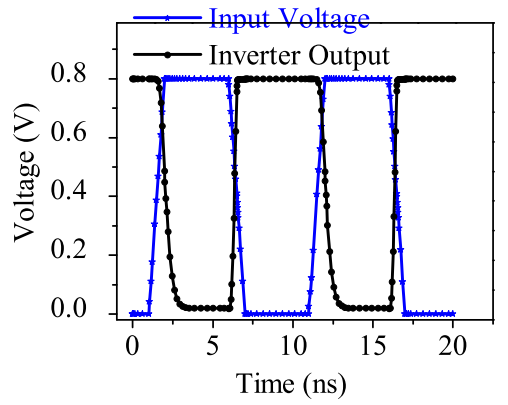

(b)

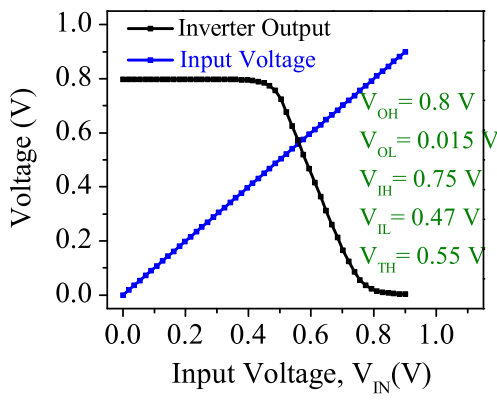

(c)

Fig. 3: (a) SETMOS inverter design using SET $\left(\mathrm{C}_{G}=0.1 \mathrm{aF}\right.$, $\mathrm{C}_{T D}=\mathrm{C}_{T S}=0.0468 \mathrm{aF}$ and $\mathrm{R}_{T}=20 \mathrm{M} \Omega$ ) and PMOS (W= $55 \mathrm{~nm}, \mathrm{~L}=22 \mathrm{~nm}$ ) (b) Transient characteristics (c) Voltage transfer characteristics [21] voltage transfer characteristics of the inverter [21] with noise margin parameters.

Fig.4 illustrates the designs of the two-input NAND, NOR, EX-OR, EX-NOR, OR, and AND logic gates. The logic gates have the same architecture in which the pull-down network is the proposed SG-SET, and the pull-up network is 22-nm PMOS [24]. For OR and AND gate, SETMOS inverter is used to invert the logic of NOR and NOR.

The transient analysis verified the logic functionality of all gates, as shown in Fig.5. NAND, NOR, OR, and AND gates are simulated with $10 \mathrm{MHz}$, while EX-OR and EX-OR gates are simulated with $4 \mathrm{MHz}$ operating frequency. The bias voltage of logic gates is $0.8 \mathrm{~V}$. The propagation delay and total power dissipation are extracted from the simulation result.
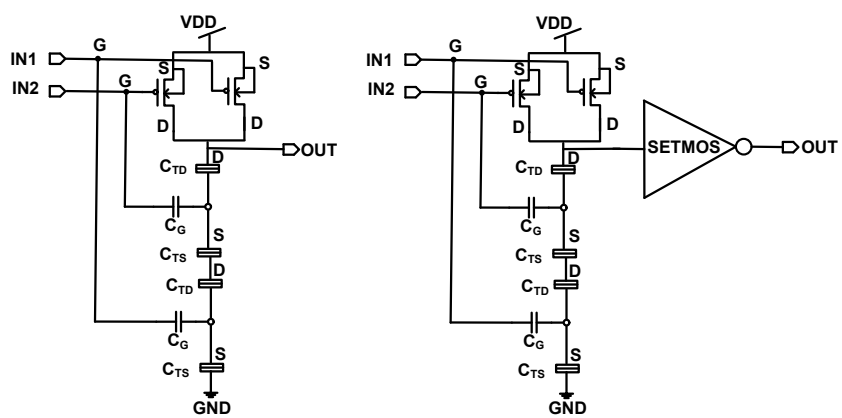

(a)
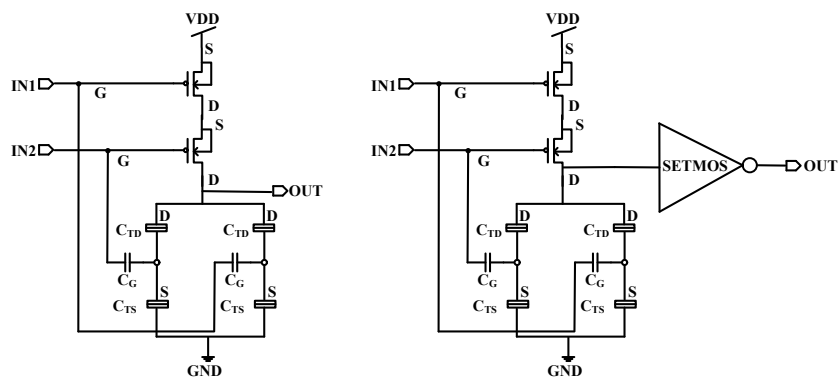

(b)
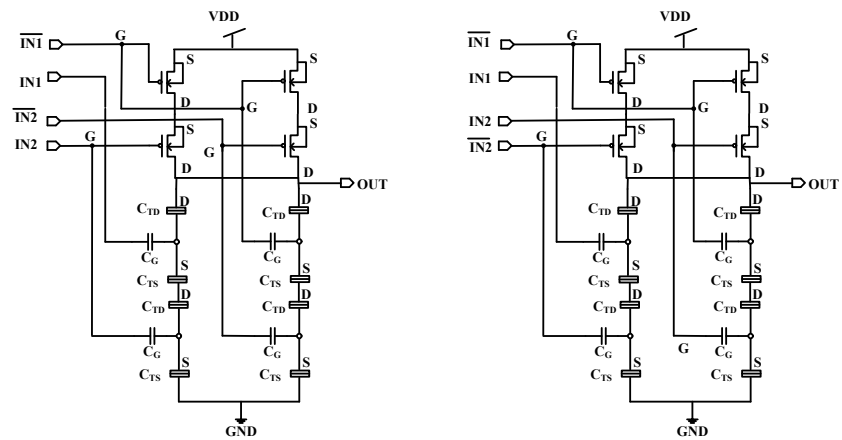

(c)

Fig. 4: Hybrid SETMOS two input (a) two input NAND and AND (b) OR and NOR (c) EX-OR and EX-NOR logic gates 


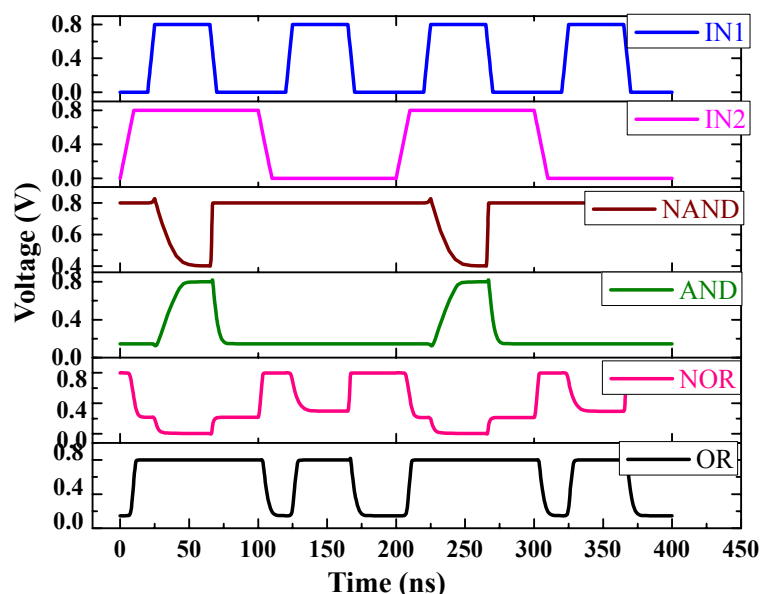

(a)

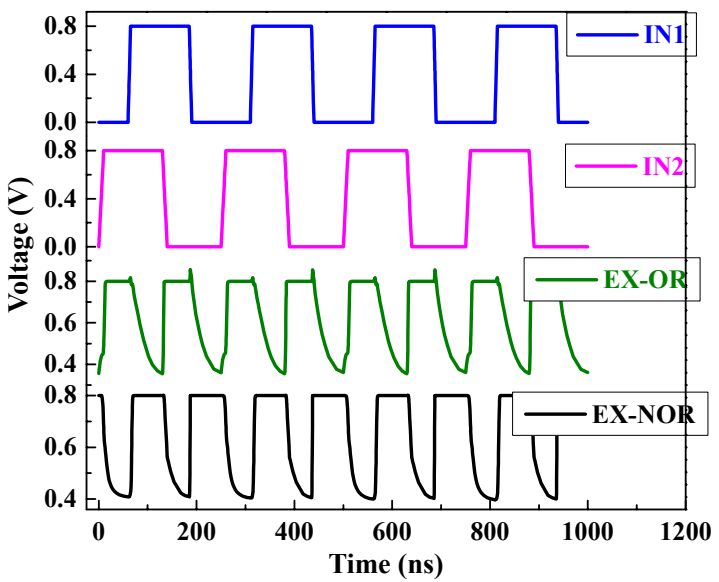

(b)

Fig. 5: Transient simulation of hybrid SETMOS two input (a) NAND, AND, NOR and OR (b) EX-OR and EX-NOR, logic gate circuits

\section{Result and Discussion}

Two input NAND, NOR, AND, OR, EX-OR, and EX-NOR gates using $22 \mathrm{~nm}$ CMOS are simulated at room temperature with the same bias $(0.8 \mathrm{~V})$ and operating frequency as hybrid SETMOS logic gates. Table. 1 and Table. 2 show the extracted propagation delay and total power dissipation along with the number of devices used for designing hybrid SETMOS and CMOS logic gates, respectively. From Table 1 and Table 2, we noted that the total power dissipation of hybrid SETMOS gates is very less than CMOS logic gates at the cost of propagation delay. The comparison of hybrid SETMOS logic gates with CMOS counterpart pointed to the decline in total power dissipation is $98.04 \%, 96.45 \%$, $94.65 \%, 93.7 \%, 92.63 \%, 93.52 \%, 95.57 \%$ for NOT, NAND, NOR, AND, OR, EX-OR, and EX-NOR gates, respectively. Hence, this technique is more beneficial for ultra-low-power applications. The novel hybridization logic circuits results
Table 1: Extracted Parameters of Hybrid SETMOS Logic Gates at Room Temperature $\left(\mathrm{V}_{D D}=0.8 \mathrm{~V}\right)$

\begin{tabular}{lllll}
\hline \multirow{2}{*}{$\begin{array}{l}\text { Logic } \\
\text { gate }\end{array}$} & Total Power & Propagation & \multicolumn{2}{c}{ No. of Devices } \\
\cline { 3 - 5 } @ 10 MHz & Delay & SET & PMOS \\
\hline NOT & $3.11 \mathrm{nW}$ & $8.9 \mathrm{~ns}$ & 1 & 1 \\
NAND & $1.4 \mathrm{nW}$ & $12.08 \mathrm{~ns}$ & 2 & 2 \\
NOR & $4.46 \mathrm{nW}$ & $3.27 \mathrm{~ns}$ & 2 & 2 \\
AND & $3.21 \mathrm{nW}$ & $12.09 \mathrm{~ns}$ & 5 & 5 \\
OR & $7.47 \mathrm{nW}$ & $4.067 \mathrm{~ns}$ & 5 & 5 \\
EX-OR & $8.68 \mathrm{nW}$ & $21.16 \mathrm{~ns}$ & 6 & 6 \\
EX-NOR & $9.44 \mathrm{nW}$ & $18.26 \mathrm{~ns}$ & 6 & 6 \\
\hline
\end{tabular}

Table 2: Extracted Parameters of CMOS Logic Gates at Room Temperature $\left(\mathrm{V}_{D D}=0.8 \mathrm{~V}\right)$

\begin{tabular}{lllll}
\hline \multirow{2}{*}{$\begin{array}{l}\text { Logic } \\
\text { gate }\end{array}$} & Total Power & Propagation & \multicolumn{2}{c}{ No. of Devices } \\
\cline { 4 - 5 } & @ $\mathbf{1 0} \mathbf{M H z}$ & Delay & NMOS & PMOS \\
\hline NOT & $159.92 \mathrm{nW}$ & $54.85 \mathrm{ps}$ & 1 & 1 \\
NAND & $39.5 \mathrm{nW}$ & $1.31 \mathrm{~ns}$ & 2 & 2 \\
NOR & $83.44 \mathrm{nW}$ & $1.28 \mathrm{ps}$ & 2 & 2 \\
AND & $48.24 \mathrm{nW}$ & $559.12 \mathrm{ps}$ & 5 & 5 \\
OR & $101.36 \mathrm{nW}$ & $4.94 \mathrm{ps}$ & 5 & 5 \\
EX-OR & $134 \mathrm{nW}$ & $559.0 \mathrm{ps}$ & 6 & 6 \\
EX-NOR & $213.52 \mathrm{nW}$ & $532.3 \mathrm{ps}$ & 6 & 6 \\
\hline
\end{tabular}

Table 3: Comparison with Other Research Work at Room Temperature $\left(\mathrm{V}_{D D}=0.8 \mathrm{~V}\right)$

\begin{tabular}{llllll}
\hline \multirow{2}{*}{ Reference } & \multicolumn{5}{c}{ Total Power Consumption } \\
\cline { 2 - 6 } & NOT & NAND & NOR & EX-OR & EX-NOR \\
\hline Venkataratnam, & 2.11 & 0.78 & 4.14 & 1.5 & 1.5 \\
$(2008[29])$ & $\mu \mathrm{W}$ & $\mu \mathrm{W}$ & $\mu \mathrm{W}$ & $\mu \mathrm{W}$ & $\mu \mathrm{W}$ \\
Parekh, & 4 & - & - & - & - \\
$(2012[27])$ & $\mathrm{nW}$ & & & & - \\
Jana, & 3.877 & - & - & - & - \\
$(2013[30])$ & $\mathrm{nW}$ & & & & \\
Abulateb, & - & 15.64 & 15.64 & 17.36 & - \\
$(2015[31])$ & & $\mathrm{nW}$ & $\mathrm{nW}$ & $\mathrm{nW}$ & \\
Chaudhri, & 2050 & - & - & - & - \\
$(2019[32])$ & $\mathrm{nW}$ & & & & \\
$\begin{array}{l}\text { Proposed Work, } \\
(2021)\end{array}$ & 3.11 & 1.4 & 4.46 & 8.68 & 9.44 \\
\hline
\end{tabular}

are also compared with the other simulated SET and CMOS hybridization simulations [27, 29-32] at same bias (0.8 V) as shown in Table 3 . The comparison explicates that the proposed logic gates' total power consumption is less than other hybridization methods at the same bias voltage.

\section{Thermal analysis of Proposed Hybrid SETMOS Logic Circuits}

The designed logic gates are further simulated at $77 \mathrm{~K}, 150$ K, $300 \mathrm{~K}, 400 \mathrm{~K}$ and $500 \mathrm{~K}$. Fig. 6 shows the test bench circuit to simulate the logic circuit for different temperatures. 
This wide range of temperature is considered to observe the thermal robustness of the proposed logic gates. The transient simulation for all logic gates has been performed at these temperatures. The propagation delay and total power dissipation are calculated from the simulation results.

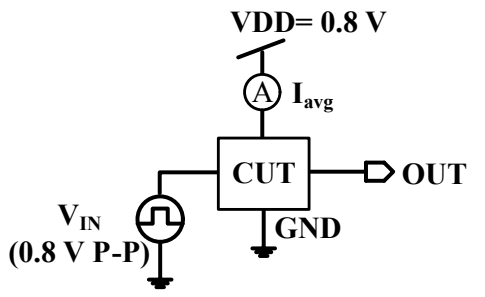

CUT: Circuit Under test Temperature: $\{77 \mathrm{~K}, 150 \mathrm{~K}, 300 \mathrm{~K}, 400 \mathrm{~K}, 500 \mathrm{~K}\}$

Power Dissipation $=I_{\text {avg }} * V_{\text {DD }}$ Propagation Delay $=1 /$ Output Frequency

Fig. 6: Test bench for thermal analysis of hybrid SETMOS logic gates

Table 4: Thermal analysis effect on total power consumption

\begin{tabular}{llllll}
\hline Logic Gate & \multicolumn{5}{c}{ Temperature } \\
\hline & $\mathbf{7 7 ~ K}$ & $\mathbf{1 5 0} \mathbf{~ K}$ & $\mathbf{3 0 0} \mathbf{~ K}$ & $\mathbf{4 0 0 ~ K}$ & $\mathbf{5 0 0} \mathbf{~}$ \\
\hline NOT & $3.88 \mathrm{nW}$ & $3.95 \mathrm{nW}$ & $4.47 \mathrm{nW}$ & $4.98 \mathrm{nW}$ & $5.22 \mathrm{nW}$ \\
NAND & $1.21 \mathrm{nW}$ & $1.23 \mathrm{nW}$ & $1.4 \mathrm{nW}$ & $1.54 \mathrm{nW}$ & $1.71 \mathrm{nW}$ \\
NOR & $3.39 \mathrm{nW}$ & $3.63 \mathrm{nW}$ & $4.46 \mathrm{nW}$ & $4.82 \mathrm{nW}$ & $6.096 \mathrm{nW}$ \\
EX-OR & $7.63 \mathrm{nW}$ & $7.79 \mathrm{nW}$ & $8.84 \mathrm{nW}$ & $9.85 \mathrm{nW}$ & $11.52 \mathrm{nW}$ \\
EX-NOR & $7.68 \mathrm{nW}$ & $7.89 \mathrm{nW}$ & $8.94 \mathrm{nW}$ & $9.94 \mathrm{nW}$ & $11.416 \mathrm{nW}$ \\
AND & $7.12 \mathrm{nW}$ & $7.3 \mathrm{nW}$ & $7.47 \mathrm{nW}$ & $8.032 \mathrm{nW}$ & $9.48 \mathrm{nW}$ \\
OR & $1.40 \mathrm{nW}$ & $1.64 \mathrm{nW}$ & $2.84 \mathrm{nW}$ & $3.92 \mathrm{nW}$ & $5.016 \mathrm{nW}$ \\
\hline
\end{tabular}

Table 5: Thermal analysis effect on propagation delay

\begin{tabular}{llllll}
\hline Logic Gate & \multicolumn{5}{c}{ Temperature } \\
\hline & $\mathbf{7 7 ~ K}$ & $\mathbf{1 5 0} \mathbf{~}$ & $\mathbf{3 0 0} \mathbf{~ K}$ & $\mathbf{4 0 0 ~ K}$ & $\mathbf{5 0 0} \mathbf{~ K}$ \\
\hline NOT & $8.32 \mathrm{~ns}$ & $8.37 \mathrm{~ns}$ & $7.67 \mathrm{~ns}$ & $7.75 \mathrm{~ns}$ & $6.06 \mathrm{~ns}$ \\
NAND & $12.92 \mathrm{~ns}$ & $11.92 \mathrm{~ns}$ & $8.94 \mathrm{~ns}$ & $7.15 \mathrm{~ns}$ & $5.48 \mathrm{~ns}$ \\
NOR & $2.84 \mathrm{~ns}$ & $2.81 \mathrm{~ns}$ & $2.96 \mathrm{~ns}$ & $3.01 \mathrm{~ns}$ & $2.7 \mathrm{~ns}$ \\
EX-OR & $29.43 \mathrm{~ns}$ & $25.32 \mathrm{~ns}$ & $16.41 \mathrm{~ns}$ & $12.54 \mathrm{~ns}$ & $3.57 \mathrm{~ns}$ \\
EX-NOR & $30.2 \mathrm{~ns}$ & $26.27 \mathrm{~ns}$ & $16.85 \mathrm{~ns}$ & $13.01 \mathrm{~ns}$ & $3.83 \mathrm{~ns}$ \\
AND & $36.13 \mathrm{~ns}$ & $34.6 \mathrm{~ns}$ & $34.3 \mathrm{~ns}$ & $33.86 \mathrm{~ns}$ & $33.37 \mathrm{~ns}$ \\
OR & $63.9 \mathrm{~ns}$ & $59.45 \mathrm{~ns}$ & $57.18 \mathrm{~ns}$ & $55.9 \mathrm{~ns}$ & $55.31 \mathrm{~ns}$ \\
\hline
\end{tabular}

Table 4 reports the results for simulated logic gates and the effect of thermal analysis on total power dissipation. In Table 5, the effect of thermal analysis on propagation delay is summarized from logic gates simulation. For all logic gates, the total power dissipation increases with the increase in temperature while the prorogation delay decreases. From the above analysis, the relation of the temperature on propagation delay and power dissipation is also plotted for all logic gates.

The nominal value of propagation delay and total power dissipation is considered at room temperature $(\mathrm{T}=300 \mathrm{~K})$, as shown in Fig.7. Also, thermal stability is observed by finding the change in parameter for change in temperature. It is analyzed that for NOT gate; the total power dissipation changes $3.75 \mathrm{pW} /{ }^{\circ} \mathrm{C}$ and propagation delay changes $3.84 \mathrm{ps} /{ }^{\circ} \mathrm{C}$. Similar calculations are made for all logic gates. For the NAND gate, the total power dissipation changes $1.55 \mathrm{pW} /{ }^{\circ} \mathrm{C}$, and propagation delay changes $20.73 \mathrm{ps} /{ }^{\circ} \mathrm{C}$. For NOR gate, the total power dissipation changes $8.18 \mathrm{pW} /{ }^{\circ} \mathrm{C}$, and propagation delay changes $0.6 \mathrm{ps} /{ }^{\circ} \mathrm{C}$. For EX-OR gate, the total power dissipation changes $43.4 \mathrm{pW} /{ }^{\circ} \mathrm{C}$, and prop-

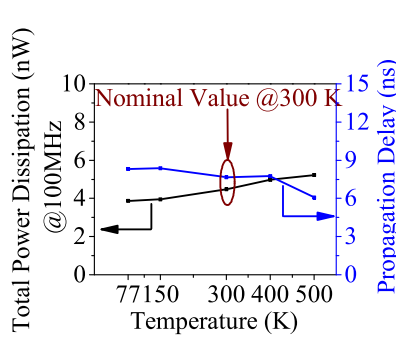

(a)

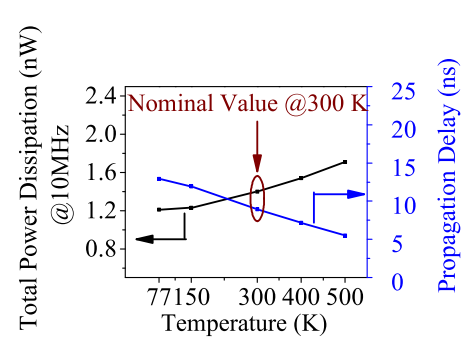

(b)

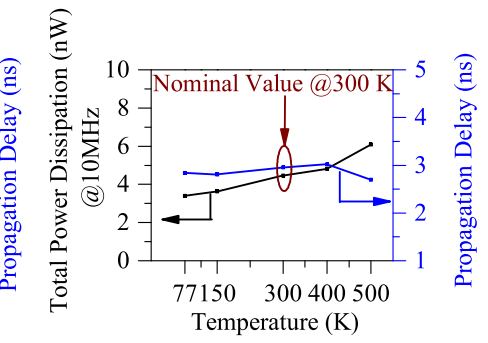

(c)

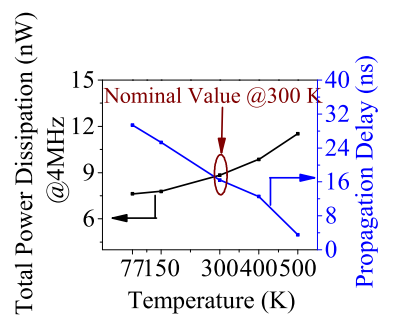

(d)

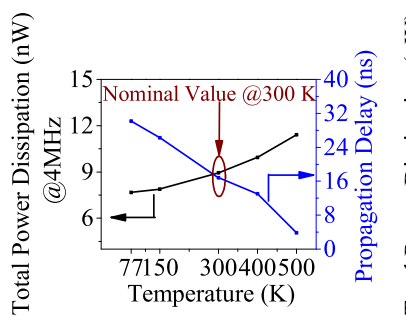

(e)

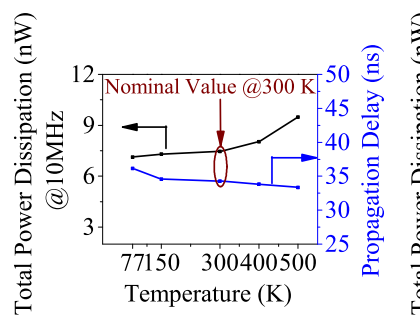

(f)

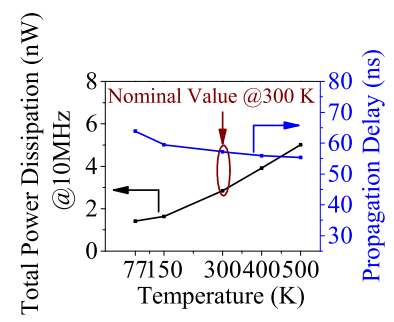

(g)

Fig. 7: Thermal analysis of logic (a) NOT (b) NAND (c) NOR (d) EX-OR (e) EX-NOR (f) AND (g) OR gates 
agation delay changes $75.84 \mathrm{ps} /{ }^{\circ} \mathrm{C}$. For EX-NOR gate, the total power dissipation changes $12.38 \mathrm{pW} /{ }^{\circ} \mathrm{C}$, and propagation delay changes $76.90 \mathrm{ps} /{ }^{\circ} \mathrm{C}$. For AND gate, the total power dissipation changes $10.88 \mathrm{pW} /{ }^{\circ} \mathrm{C}$, and propagation delay changes $11.04 \mathrm{ps} /{ }^{\circ} \mathrm{C}$. For OR gate, the total power dissipation changes $10.05 \mathrm{pW} /{ }^{\circ} \mathrm{C}$, and propagation delay changes $5.49 \mathrm{ps} /{ }^{\circ} \mathrm{C}$. These values support the excellent thermal stability of novel hybrid SETMOS logic gates.

\section{Conclusion}

The proposed SG-SET and hybrid SETMOS techniques are effective in ultra-low-power consumption, area, and scalability. The room temperature operation, CMOS bias, and CMOS process compatibility are the advantages of the hybrid SETMOS technique. Using this architecture, we have explored and investigated logic inverter, NAND, NOR, AND, OR, EX-OR, and EX-NOR gates. The functionality of logic gates is verified using transient analysis. All logic gates are also simulated using 22-nm CMOS technology using the same simulation environment. We observed more than 90 $\%$ less power consumption by hybrid SETMOS logic gates than CMOS logic gates. Also, the proposed technique is found better compared to other hybridized techniques at the same bias. The thermal analysis has also been performed for all logic gates for $77 \mathrm{~K}, 150 \mathrm{~K}, 300 \mathrm{~K}, 400 \mathrm{~K}$, and 500 $\mathrm{K}$ temperatures. We found the change in power dissipation for all logic gates is in the range of $\mathrm{pW} /{ }^{\circ} \mathrm{C}$, and the change in propagation delay is in the range of $\mathrm{ps} /{ }^{\circ} \mathrm{C}$. The obtained results reveal the robustness of our circuits against temperature variation. Hence, we analyzed that the logic gates can be further implemented in ultra-low power applications.

\section{ACKNOWLEDGMENT}

The authors would like to thank the SMDP-C2SD project sponsored by Meity, the Government of India, for providing tool support to conduct this research.

\section{Author Contributions}

Design, Methodology, Formal analysis, and investigation, Validation, Writing - original draft preparation: [Raj Shah]; Conceptualization, Resources, Supervision: [Rutu Parekh and Rasika Dhavse]

\section{Funding}

Not Applicable.

\section{Data Availability}

Not Applicable.

\section{Code Availability}

Not Applicable.

\section{Statements and Declarations}

Conflicts of Interest/Competing Interests The authors have no relevant financial or non-financial interests to disclose.

\section{Authors' Information}

Not Applicable.

\section{Ethics Approval and Consent to Participate}

Not Applicable.

\section{Consent for Publication}

Not Applicable.

\section{References}

1. A. Chen, in 2014 IEEE International Conference on IC Design Technology (2014), pp. 1-4. DOI 10.1109/ ICICDT.2014.6838616

2. ITRS. Emerging research devices. http://http://www.itrs2.net/itrsreports.html (2015)

3. C. Hamaguchi, Basic semiconductor physics (Springer Science \& Business Media, 2009)

4. G.W. Hanson, Fundamentals of nanoelectronics (Pearson/Prentice Hall Upper Saddle River, 2008)

5. K. Likharev, IEEE Transactions on Magnetics 23(2), 1142 (1987). DOI 10.1109/TMAG.1987.1065001

6. S.M. Adrian M. Ionescu, Hybrid CMOS SingleElectron-Transistor Device and Circuit Design (ARTECH HOUSE, INC.685 Canton Street Norwood, MA 02062, 2006)

7. Z.A.K. Durrani, A.C. Irvine, H. Ahmed, K. Nakazato, Applied Physics Letters 74(9), 1293 (1999). DOI 10. 1063/1.123528

8. V. Ray, R. Subramanian, P. Bhadrachalam, L.C. Ma, C.U. Kim, S.J. Koh, Nature nanotechnology 3(10), 603 (2008). Doi: 10.1038/nnano.2008.267 
9. K. Uchida, J. Koga, R. Ohba, A. Toriumi, IEEE Transactions on Electron Devices 50(7), 1623 (2003). DOI 10.1109/TED.2003.813909

10. S. Mahapatra, V. Vaish, C. Wasshuber, K. Banerjee, A.M. Ionescu, IEEE Transactions on Electron Devices 51(11), 1772 (2004). DOI 10.1109/TED.2004.837369

11. S. Ecoffey, V. Pott, S. Mahapatra, D. Bouvet, P. Fazan, A. Ionescu, Microelectronic Engineering 78-79, 239 (2005). DOI https://doi.org/10.1016/j.mee.2004.12.033

12. V. Joshi, A.O. Orlov, G.L. Snider, Journal of Vacuum Science \& Technology B: Microelectronics and Nanometer Structures Processing, Measurement, and Phenomena 26(6), 2587 (2008). Doi: http: //dx . doi . org/10.1116/1.2978877

13. C. Dubuc, J. Beauvais, D. Drouin, IEEE transactions on nanotechnology 7(1), 68 (2008). Doi: 10.1109/ TNANO .2007 .913430

14. C. Dubuc, A. Beaumont, J. Beauvais, D. Drouin, SolidState Electronics 53(5), 478 (2009). DOI https://doi. org/10.1016/j.sse.2009.03.003

15. Y.C. Lee, V. Joshi, A.O. Orlov, G.L. Snider, Journal of Vacuum Science \& Technology B 28(6), C6L9 (2010). DOI 10.1116/1.3498748. URL https://doi.org/ 10.1116/1.3498748

16. R. Parekh, J. Beauvais, D. Drouin, Microelectronics Journal 45(8), 1087 (2014). Doi: https : //doi .org/ 10.1016/j.mejo.2014.05.020

17. A. Ghosh, A. Jain, N.B. Singh, S.K. Sarkar, Journal of Computational Electronics 15, 400 (2016). DOI https: //doi.org/10.1007/s10825-015-0790-1

18. R. Shah, R. Dhavse, in Proceedings of the Nanotech France 2018 International Conference (Nanotech France 2018) (2018), pp. 37-40

19. R. Shah, R. Parekh, R. Dhavse, in International Conference on Advances in VLSI \& Embedded Systems (AVES2019), Surat (2019)

20. R. Shah, R. Dhavse, Silicon , (2020). DOI http://dx. doi.org/10.1007/s12633-020-00461-X

21. R. Shah, R. Parekh, R. Dhavse, Journal of Computational Electronics 20(1), 218 (2021). DOI 10.1007/ s10825-020-01622-2. URL https://doi.org/10. 1007/s10825-020-01622-2

22. Synopsys, Sentaurus ${ }^{T M}$ Device User Guide (2015)

23. C. Wasshuber, Computational Single-Electronics (Springer, Vienna Copyright Information: SpringerVerlag/Wien 2001). DOI https://doi.org/10.1007/ 978-3-7091-6257-6

24. Predective technology model. http://ptm.asu.edu/

25. Cadence design systems. http://www.cadence. com/

26. R. Shah, R. Parekh, R. Dhavse, in International Conference on EMERGING TECHNOLOGY TRENDS in ELECTRONICS COMMUNICATION and NETWORK-
ING (ET2ECN-2020),Surat (2020)

27. R. Parekh, A. Beaumont, J. Beauvais, D. Drouin, IEEE Transactions on Electron Devices 59(4), 918 (2012). DOI 10.1109/TED.2012.2183374

28. K. A.S.Sedra, A. Chandorkar, Microelectronics Circuits (Oxford University Press, 2011)

29. A. Venkataratnam, A. Goel, Microelectronics Journal 39(12), 1461 (2008). DOI https://doi.org/10.1016/j. mejo.2008.08.002

30. A. Jana, N.B. Singh, J. Sing, S.K. Sarkar, Microelectronics Reliability 53(4), 592 (2013). DOI https://doi. org/10.1016/j.microrel.2012.11.001

31. M.M. Abutaleb, Journal of Computational Electronics 14, 329 (2015). DOI https://doi.org/10.1007/ s10825-014-0660-2

32. J.R. Chaudhri, D. Gautam, Silicon 11, 751 (2019). DOI https://doi.org/10.1007/s12633-018-9834-z 